Article

\title{
Triple Layer Tungsten Trioxide, Graphene, and Polyaniline Composite Films for Combined Energy Storage and Electrochromic Applications
}

\author{
Hailong Lyu ${ }^{1,2}$ (D) \\ 1 Chemical Sciences Division, Oak Ridge National Laboratory, Oak Ridge, TN 37831, USA; hlyu@utk.edu \\ 2 Department of Chemistry, University of Tennessee, Knoxville, TN 37996, USA
}

Received: 25 November 2019; Accepted: 24 December 2019; Published: 30 December 2019

\begin{abstract}
Different polyaniline (PANI)-based hybrid films were successfully prepared by electro-polymerizing aniline monomers onto pre-spin-coated indium tin oxide (ITO) glass slides with $\mathrm{WO}_{3}$, graphene, or $\mathrm{WO}_{3}$ /graphene films. Comparing with pristine PANI, the shifts of the characteristic peaks of PANI-based nanocomposites in UV-visible absorption spectra (UV-vis) and Fourier transform infrared spectroscopy (FT-IR) indicate the chemical interaction between the PANI matrix and the nanofillers, which is also confirmed by the scanning electron microscope (SEM) images. Corresponding coloration efficiencies were obtained for the $\mathrm{WO}_{3} / \mathrm{PANI}\left(40.42 \mathrm{~cm}^{2} \mathrm{C}^{-1}\right)$, graphene/PANI $\left(78.64 \mathrm{~cm}^{2} \mathrm{C}^{-1}\right)$, and $\mathrm{WO}_{3} /$ graphene/PANI $\left(67.47 \mathrm{~cm}^{2} \mathrm{C}^{-1}\right)$ films, higher than that of the pristine PANI film $\left(29.4 \mathrm{~cm}^{2} \mathrm{C}^{-1}\right)$, suggesting positive effects of the introduced nanofillers on the electrochromic performance. The areal capacitances of the films were observed to increase following the order as bare $\mathrm{WO}_{3}<\mathrm{WO}_{3} /$ graphene $<$ pristine PANI $<\mathrm{WO}_{3} / \mathrm{PANI}$ $<$ graphene/PANI $<\mathrm{WO}_{3}$ /graphene/PANI films from both the cyclic voltammogram (CV) and galvanostatic charge-discharge (GCD) results. The enhanced energy storage and electrochromic performances of the PANI-based nanocomposite films can be attributed to the capacitance contributions of the introduced nanofillers, increased PANI amount, and the rougher morphology due to the embedment of the nanofillers into the PANI matrix. This extraordinary energy storage and electrochromic performances of the $\mathrm{WO}_{3}$ /graphene/PANI film make it a promising candidate for combined electrochromic and energy storage applications.
\end{abstract}

Keywords: polyaniline; $\mathrm{WO}_{3}$; graphene; electrochromic; electrochemical energy storage

\section{Introduction}

Energy shortage and environmental pollution have been two major subjects of modern society, which urgently requires developing clean, efficient, and renewable sources of energy, as well as advanced technologies associated with energy storage and conversion [1-3]. As a promising novel energy storage device with fast charging-discharging rate and extremely long cycling life, electrochemical supercapacitor possesses not only higher energy density than conventional dielectric capacitors but also higher power density than common batteries [4,5]. Electrochemical supercapacitors include two typical categories based on different charge storage mechanisms, that is, electric double-layer capacitors (EDLCs) with a non-Faradic process through the ion adsorption between the interfaces of electrodes and electrolyte, and pseudo-capacitors with a Faradic process via fast surface redox reaction [6]. Carbon materials usually employed as EDLCs exhibit excellent cycling life ( $>10^{5}$ cycles) but limited capacitance. In contrast, metal oxides and conducting polymers as main materials for pseudo-capacitors always possess much larger capacitances but the shrinkage and swelling lead to much shorter cycling life. In order to overcome their corresponding deficiencies, it is proposed that 
the combination of EDLCs materials with pseudo-capacitive materials is an excellent choice since this approach can take advantage of both the long cycling life of EDLCs and high capacitance merits of metal oxides [7].

Meanwhile, electrochromism (EC) has also attracted intense research attention over the last few decades, where the material color changes with electrochemical reactions [8,9]. The persistent but reversible color change of electrochromic materials can be easily controlled by a temporarily employed electrical potential [10], showing wide potential applications such as smart windows, display devices, vehicle sunroofs, and antiglare mirrors for cars [11-13]. For example, the light transmittance or reflectance properties of electrochromic windows can be adjusted by voltage through reversible lithium intercalation, allowing the controllable heat transfer and lighting conditions [14]. Various types of materials have been reported to show electrochromic properties, such as transition metal oxides, mixed-valence materials, organic molecules, and conjugated polymers [15-17].

Among all the materials for supercapacitor and electrochromic applications, conducting polymers belonging to both categories have received a lot of research interests because of their tunable electrical properties, flexibility, and high processability within solution [18]. Among all the polymers, solution-processable conductive polymers can be proceeded through a low-cost approach to fabricate thin-film electrodes, offering adjustable thickness, high conductivity, excellent optical transparency, and superior electrochromism $[19,20]$. Particularly, polyaniline (PANI) has attracted extensive attention by the good electrochemical and thermal stabilities, tunable properties, low-cost, and high conductivity [21,22]. The pseudo-capacitance and corresponding color change from the various redox reactions make PANI a promising candidate for combined electrochemical capacitor and electrochromic applications [23]. However, multiple electrochromic materials or "multicoloring" have to be applied to increase the range of available colors and reproduce high-quality electrochromism in such devices. One straightforward method is to mix two discrete colors, which can be achieved by applying two kinds of electrochromic materials with complementary colors deposited onto two different working electrodes $[12,24,25]$. Furthermore, the switching rate of electrochromic films could be improved by faster ion transport since it is a prerequisite for electrochromic materials to maintain electroneutrality that ions be transported into and out of the film during redox reactions [26]. Therefore, uniform and tunable porous structure is a beneficial feature enabling facile ion transport and redox-active films [8]. Nowadays, tungsten trioxide $\left(\mathrm{WO}_{3}\right)$ as a typical electrochromic material with certain pseudocapacitive property have been widely investigated and demonstrated promising application potentials for electrochromic and supercapacitor electrodes [27-30]. Therefore, the combined $\mathrm{WO}_{3}$ with PANI is expected to give multicolored and enhanced energy storage performances due to the combined electrochromic and pseudocapacitive properties as well as the resulted porous morphology. However, since PANI and $\mathrm{WO}_{3}$ exhibit bad cycling stabilities during the redox reaction [31,32], carbon materials are always integrated into the nanocomposites because of their excellent cycling stability [33-36]. Graphene with the two-dimensional (2D) carbon structure can well meet the requirement owing to its unique electrical, chemical, thermal, and mechanical properties [37-39]. Especially, graphene has been demonstrated to stabilize the conducting polymer by forming a certain relationship thus enhancing the conductivity, energy storage ability, and cycling stability of pristine polymers [40-43]. All in all, the introduction of either $\mathrm{WO}_{3}$ or graphene is expected to have positive effects on the electrochromic and supercapacitor performance of the pristine PANI films.

In this work, we have successfully synthesized different hybrid $\mathrm{WO}_{3}$, graphene, and PANI films by employing combined spin coating and electro-polymerization method. The interactions between the specific components and the morphologies of the synthesized different hybrid films (bare $\mathrm{WO}_{3}$, pristine PANI, double layer $\mathrm{WO}_{3} /$ graphene, double layer $\mathrm{WO}_{3} / \mathrm{PANI}$, double layer graphene/PANI, and triple layer $\mathrm{WO}_{3}$ /graphene/PANI films) have been successfully investigated by various characterization methods. Their energy storage and electrochromic performances were also studied. All the PANI-based hybrid films exhibit greatly enhanced energy storage abilities and coloration efficiencies compared to the pristine PANI, demonstrating positive effects of the nanofillers. The triple layer $\mathrm{WO}_{3} /$ graphene/PANI 
film shows great potential for combined energy storage and electrochromic applications. To the best of our knowledge, comprehensive characterizations and studies of different hybrid $\mathrm{WO}_{3}$, graphene, and PANI films for energy storage and electrochromic applications have not been reported.

\section{Materials and Methods}

\subsection{Materials}

Aniline $\left(\mathrm{C}_{6} \mathrm{H}_{7} \mathrm{~N}, \geq 99.0 \%\right)$, sulfuric acid $\left(\mathrm{H}_{2} \mathrm{SO}_{4}, 95.0-98.0 \%\right)$, hydrogen peroxide solution (PERDROGEN囚30\% $\mathrm{H}_{2} \mathrm{O}_{2}(\mathrm{w} / \mathrm{w})$ ), ethanol (HPLC, 99.8\%), and ammonium hydroxide $\left(\mathrm{NH}_{4} \mathrm{OH}\right.$, $28.86 \mathrm{wt} \%$ ) were all purchased from Fisher Scientific (Hampton, VA, USA). Tungsten oxide $\left(\mathrm{WO}_{3}\right.$, 99.9+\%, 40-50 nm, Stock \# 5506BD, CAS \# 1314-35-8, Lot \# 5506-021115) were purchased from Nanostructured \& Amorphous Materials, Inc. (Katy, TX, USA). Graphene was provided by Celtig LLC (Knoxville, TN, USA). The microscope glass slides and indium tin oxide (ITO) coated glass slides were also obtained from Fisher Scientific (Hampton, VA, USA). Before the usage of the ITO coated glass slides, they were first sonicated in ethanol for $10 \mathrm{~min}$, and then immersed in an aqueous solution containing $4.0 \mathrm{~mL} \mathrm{NH}_{4} \mathrm{OH}, 4.0 \mathrm{~mL} \mathrm{H}_{2} \mathrm{O}_{2}$ and $20.0 \mathrm{~mL}$ deionized water for $10 \mathrm{~min}$. Finally, the ITO glasses were sonicated in deionized water for another $10 \mathrm{~min}$ and dried naturally. Deionized water was used throughout the experiments.

\subsection{Thin Film Electrode Preparation}

Six species of films as bare $\mathrm{WO}_{3}$, double layer $\mathrm{WO}_{3}$ /graphene, pure PANI, double layer graphene/PANI, double layer $\mathrm{WO}_{3} / \mathrm{PANI}$, and triple layer $\mathrm{WO}_{3} /$ graphene/PANI were synthesized through employing a combined spin coating and electro-polymerization method, respectively. For the synthesis of $\mathrm{WO}_{3}$ film, $5.0 \mathrm{mg} \mathrm{WO}$ was dispersed in $10.0 \mathrm{~mL}$ ethanol solution under $30 \mathrm{~min}$ sonication. The $\mathrm{WO}_{3}$ film was prepared by drop casting about $1.0 \mathrm{~mL} \mathrm{WO}$ suspension onto the ITO glass and maintained at $2000 \mathrm{rpm}$ for $20 \mathrm{~s}$. $\mathrm{WO}_{3} /$ graphene film was synthesized by continued drop casting another $1.0 \mathrm{~mL}$ graphene suspension $(5.0 \mathrm{mg}$ graphene dispersed in $10.0 \mathrm{~mL}$ ethanol solution undergoing $30 \mathrm{~min}$ sonication) on the synthesized $\mathrm{WO}_{3}$ film and maintained at $2000 \mathrm{rpm}$ for another $20 \mathrm{~s}$. The electro-polymerization of aniline onto the as-treated ITO glass or formed $\mathrm{WO}_{3}$, graphene, or $\mathrm{WO}_{3}$ /graphene films were performed on an electrochemical working station VersaSTAT 4 potentiostat (Princeton Applied Research, Oak Ridge, TN, USA). A typical three electrode electrochemical cell was employed, in which a saturated calomel electrode (SCE) served as the reference electrode, a platinum $(\mathrm{Pt})$ mesh served as the counter electrode and the spin coated ITO glass or bare ITO glass slide with an effective area of $6.0 \mathrm{~cm}^{2}$ served as the working electrode. A typical electrochemical polymerization was performed 10 cycles scanned back and forth from 0 to $+1.2 \mathrm{~V}$ vs. SCE at a scan rate of $50 \mathrm{mV} / \mathrm{s}$ in $0.5 \mathrm{M} \mathrm{H}_{2} \mathrm{SO}_{4}$ aqueous solution containing $0.5 \mathrm{M}$ aniline. All the films were dried naturally overnight.

\subsection{Characterizations}

The morphologies of the thin films grown on the ITO glass slides were characterized by scanning electron microscope (SEM, Hitachi S4300, Tokyo, Japan) and atomic force microscopy (AFM, Agilent 5600 system with multipurpose $90 \mathrm{~mm}$ scanner, Santa Clara, CA, USA). The thickness of the thin films grown on the ITO glass slides were also determined by AFM. Imaging of AFM was done in acoustic ac mode (AAC) using a silicon tip with a force constant of $2.8 \mathrm{~N} / \mathrm{m}$ and a resonance frequency of $70 \mathrm{kHz}$. The FT-IR spectrometer coupled with an ATR accessory (Vector 22, Bruker Inc., Billerica, MA, USA) was used to characterize the surface functionality of the thin films grown on the ITO glass slides in the range of 2000 to $500 \mathrm{~cm}^{-1}$ at a resolution of $4 \mathrm{~cm}^{-1}$. The UV-vis of the films deposited on the ITO coated glass slide were observed in the range of $200-800 \mathrm{~nm}$ at room temperature using a UV-visible spectrophotometer (Jasco V-670 spectrophotometer and spectralon was used as a reference, Easton, MD, USA). A long path length home-made spectro electrochemical cell with Teflon cell body with front and rear windows clapped with two steel plates was used where the ITO glass slide 
was used as the working electrode for energy storage and optical characterizations. In a standard three-electrode system, the electrochemical behaviors of the PANI-based nanocomposites films were investigated by $\mathrm{CV}$ scanned from -0.2 to $0.8 \mathrm{~V}$ vs. SCE at a series of scan rates and galvanostatic charge-discharge measurements from 0 to $0.8 \mathrm{~V}$ with different current densities. The electrochemical impedance spectroscopy (EIS) was carried out in the frequency range from 100,000 to $0.01 \mathrm{~Hz}$ at a $5 \mathrm{mV}$ amplitude referring to the open circuit potential (OCP) on the same electrochemical working station VersaSTAT 4 potentiostat. The cycling stabilities of the PANI-based films were also investigated by evaluating the capacitance retentions by running 1000 galvanostatic charge-discharge cycles. The spectroelectrochemistry measurements were performed on a Jasco V-670 spectrophotometer coupled with the potentiostat for applying electrochemical potentials. The in situ chronocoulometry (CC) were conducted under a square-wave voltage of 0.8 and $-0.2 \mathrm{~V}$ with a pulse width of $20 \mathrm{~s}$ using the electrochemical working station VersaSTAT 4 potentiostat.

\section{Results and Discussion}

\subsection{Thin Film Electrode Preparation}

Figure 1 shows the potentiodynamic electro-polymerization growth of PANI onto the (a) bare ITO, (b) graphene-coated ITO, (c) $\mathrm{WO}_{3}$-coated ITO, and (d) double layer $\mathrm{WO}_{3} /$ graphene-coated ITO. The PANI film are deposited on the glass by sweeping the potential between 0 and $1.2 \mathrm{~V}$ at a scan rate of $50 \mathrm{mV} / \mathrm{s}$ in $0.5 \mathrm{M} \mathrm{H}_{2} \mathrm{SO}_{4}$ aqueous solution containing $0.5 \mathrm{M}$ aniline. The film growth can be clearly verified by the continuously increased current with the $\mathrm{CV}$ cycles. Similar CV curves except different anodic current peaks are obtained for these PANI-based nanocomposites films. The anodic irreversible peaks start at around $+0.9 \mathrm{~V}$, corresponding to the oxidation of aniline monomers and the initiation of the PANI electro-polymerization. However, it is noted that the anodic peak current densities of graphene/PANI (Figure $1 \mathrm{~b}, 1.53 \mathrm{~mA} / \mathrm{cm}^{2}$ ) and $\mathrm{WO}_{3} /$ graphene/PANI (Figure $1 \mathrm{~d}, 1.55 \mathrm{~mA} / \mathrm{cm}^{2}$ ) are much higher than that of pristine PANI (Figure 1a, $0.88 \mathrm{~mA} / \mathrm{cm}^{2}$ ), which can be attributed to the improved electrical conductivity caused by the introduced graphene. In contrast, $\mathrm{WO}_{3} / \mathrm{PANI}$ shows decreased anodic peak current density (Figure $1 \mathrm{c}, 0.76 \mathrm{~mA} / \mathrm{cm}^{2}$ ) compared to pristine PANI film because of the increased resistance of $\mathrm{WO}_{3}$ film on the ITO.

In addition, the mass of the electropolymerized PANI onto the substrate can be roughly estimated through the total Faradic charges consumed in the electro-polymerization assuming that 2.5 electrons for each aniline monomer in emeraldine, as the following Equation (1):

$$
m=C M_{m} / 2.5 F
$$

where $m$ is the mass of PANI polymerized onto the substrate, gram (g); $C$ is the total Faradic charges consumed in the electro-polymerization, coulomb (C); $M_{m}$ is the molecular mass of aniline monomers $(93.13 \mathrm{~g} / \mathrm{mol})$; and $F$ is Faraday constant $(96,485 \mathrm{C} / \mathrm{mol})$. About 14.6, 28.6, 12.3, and $27.8 \mu \mathrm{g}$ PANI polymers were calculated for the pristine $\mathrm{PANI}, \mathrm{WO}_{3} / \mathrm{PANI}$, graphene/PANI, and $\mathrm{WO}_{3} /$ graphene/PANI films, respectively. The fewer and higher amount of PANI in the $\mathrm{WO}_{3} / \mathrm{PANI}$ and graphene/PANI films further confirm the increased and decreased resistance caused by the introduced $\mathrm{WO}_{3}$ and graphene, respectively. 

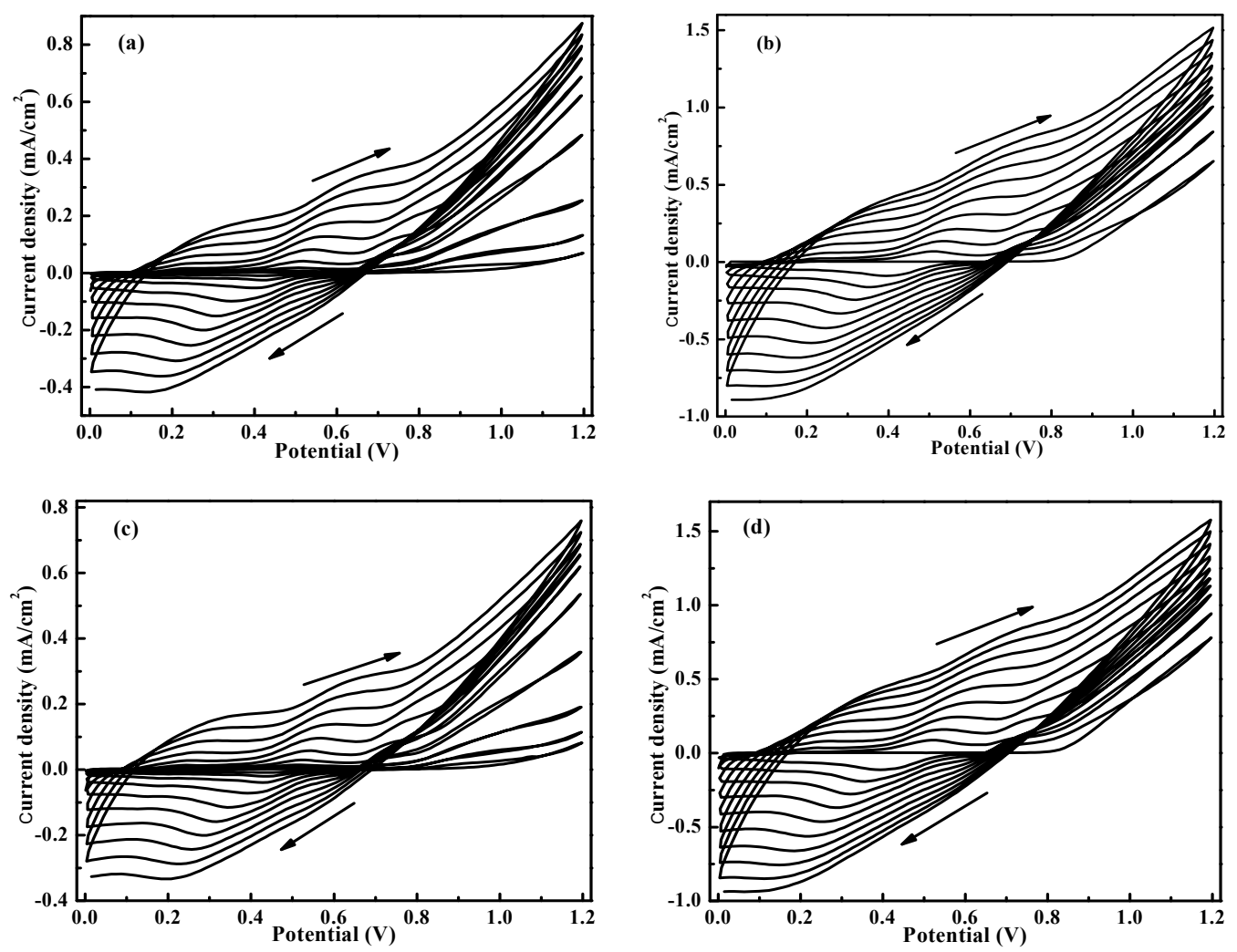

Figure 1. Electro-polymerization synthesis of polyaniline (PANI) onto (a) bare indium tin oxide (ITO) glass, (b) graphene-coated ITO glass, (c) $\mathrm{WO}_{3}$-coated ITO glass, and (d) double layer $\mathrm{WO}_{3}$ /graphene-coated ITO glass at a scan rate of $50 \mathrm{mV} / \mathrm{s}$ in $0.5 \mathrm{M} \mathrm{H}_{2} \mathrm{SO}_{4}$ aqueous solution containing $0.5 \mathrm{M}$ aniline.

\subsection{Materials Characterization}

In order to characterize the relationships between nanofillers and PANI matrix as well as the inherent composition of the nanocomposites, UV-Vis and FT-IR are conducted and shown in Figure 2 as bare $\mathrm{WO}_{3}$, double layer $\mathrm{WO}_{3} / \mathrm{PANI}$, pristine PANI, double layer graphene/PANI, double layer $\mathrm{WO}_{3} / \mathrm{PANI}$, and triple layer $\mathrm{WO}_{3} /$ graphene/PANI. Figure $2 \mathrm{~A}$ shows the UV-vis conducted in the wavelength range of $200-800 \mathrm{~nm}$. The characteristic peak of PANI centering around $240 \mathrm{~nm}$ is missing for bare $\mathrm{WO}_{3}$ and double layer $\mathrm{WO}_{3}$ /graphene films compared with that of the PANI-based ones, indicating the successful deposition of PANI in the other four films. Furthermore, a clear shift of the characteristic peak is observed for all the PANI-based nanocomposites, indicating the existence of chemical bonds between the PANI matrix and $\mathrm{WO}_{3}$ particles. The nitrogen atoms in PANI are inferred to possibly form coordinated compounds with the exposed tungsten atoms on the surface of $\mathrm{WO}_{3}$. The strong coordination bonds between the nitrogen atom and the tungsten atom might cause the observed peak shifts. FT-IR as a strong technique probing the inherent composition and inner relationships of the PANI-based nanocomposites is carried out and shown in Figure 2B. Even though the amounts of PANI on the tested area for each film are relatively too low to show strong enough signals, all the FT-IR spectra display similar peaks around 900,1000 , and $1100 \mathrm{~cm}^{-1}$, corresponding to the characteristic peaks of PANI [21,22]. Moreover, the strength of FT-IR peaks in Figure 2B shows an obvious trend of graphene/PANI $>$ PANI $>\mathrm{WO}_{3} /$ graphene/PANI $>\mathrm{WO}_{3} / \mathrm{PANI}$, which is consistent with the PANI amounts calculated above. 

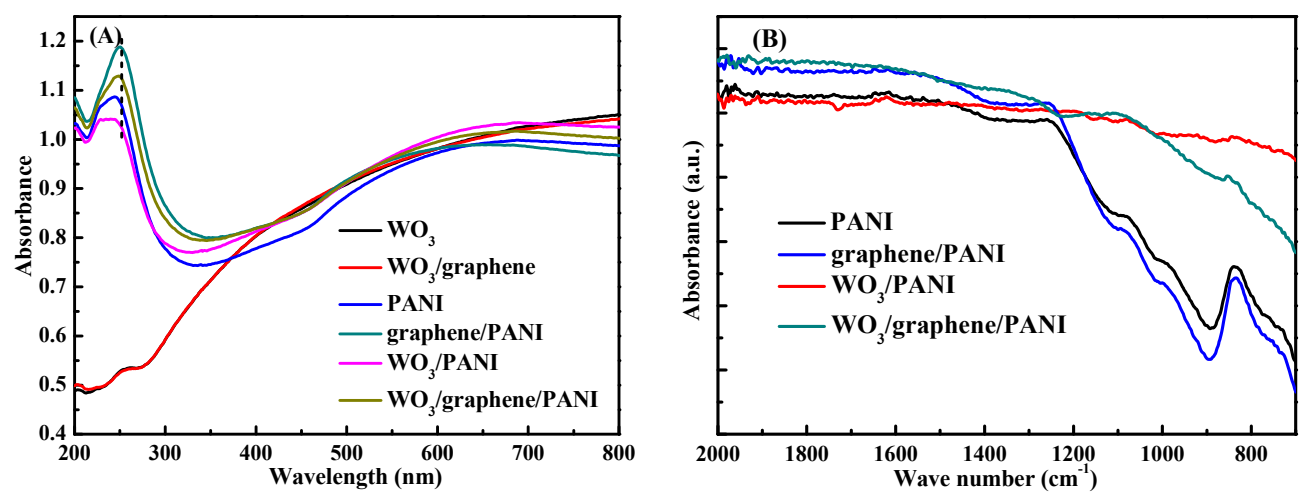

Figure 2. (A) UV-vis and (B) FT-IR spectra of bare $\mathrm{WO}_{3}$ film, double layer $\mathrm{WO}_{3}$ /graphene film, pristine PANI film, double layer graphene/PANI film, double layer $\mathrm{WO}_{3} / \mathrm{PANI}$ film, and triple layer $\mathrm{WO}_{3}$ /graphene/PANI film, respectively.

The morphologies of the synthesized hybrid films have been characterized by SEM as shown in Figure 3, which represents the SEM images of (a) pristine PANI, (b) graphene/PANI, (c) $\mathrm{WO}_{3} / \mathrm{PANI}$, and (d) $\mathrm{WO}_{3} /$ graphene/PANI films, respectively. The high magnifications of the corresponding SEM images are shown as the insets. For pristine PANI, Figure 3a, the short fiber-liked PANI is successfully deposited on the ITO glass slide through this electro-polymerization method and form a porous PANI matrix. The PANI matrix is also clearly confirmed by the magnification of this SEM image shown as inset in Figure 3a. Various morphologies of PANI can be obtained by adjusting the conditions of the electrochemical polymerization process, which will further affect the electrochemical performance of the PANI-based films. Nevertheless, the porous PANI network made by nanofibrous PANI is capable to provide not only high surface area but also transmission channels for electrons, which is supposed to be beneficial for the electrochemical performance of the PANI-based films. For the graphene/PANI film, Figure 3b, graphene sheets and PANI matrix are both seen and uniformly distributed on the ITO glass. Furthermore, a closer insight shows clear interactions between the PANI fibers and graphene sheets shown as inset in Figure 3b. Similarly, for $\mathrm{WO}_{3} / \mathrm{PANI}$, Figure 3c, $\mathrm{WO}_{3}$ nanoparticles and PANI matrix are also uniformly distributed on the ITO glass with clear interaction between $\mathrm{WO}_{3}$ particles and PANI fibers, which is also confirmed from the magnification of Figure 3c. Finally, for the triple layer $\mathrm{WO}_{3}$ /graphene/PANI, Figure 3d, both graphene sheets and $\mathrm{WO}_{3}$ particles are clearly seen to distribute in the PANI matrix, the interactions are also confirmed by the close wrapping of PANI fibers on graphene sheets and $\mathrm{WO}_{3}$ particles shown as inset in Figure 3d. The interactions between the PANI matrix and nanofillers are consistent with the FT-IR and UV-vis analysis. In addition, the morphologies and the layer thickness are also investigated by AFM as shown in Figure S1; below of each is the height profile of the corresponding film. For bare $\mathrm{WO}_{3}$ film, Figure S1a, the thickness is not a constant value because of the random distribution of $\mathrm{WO}_{3}$ nanoparticles. In contrast, other films have constant thickness values based on the corresponding profiles. The thickness of the synthesized PANI-based films follows an order as $\mathrm{WO}_{3} /$ graphene/PANI $(\sim 33 \mathrm{~nm})>\mathrm{WO}_{3} / \mathrm{PANI}(\sim 30 \mathrm{~nm})>$ graphene/PANI $(\sim 22 \mathrm{~nm})>$ pristine PANI $(\sim 20 \mathrm{~nm})$, which is consistent with the composition of the synthesized films. 

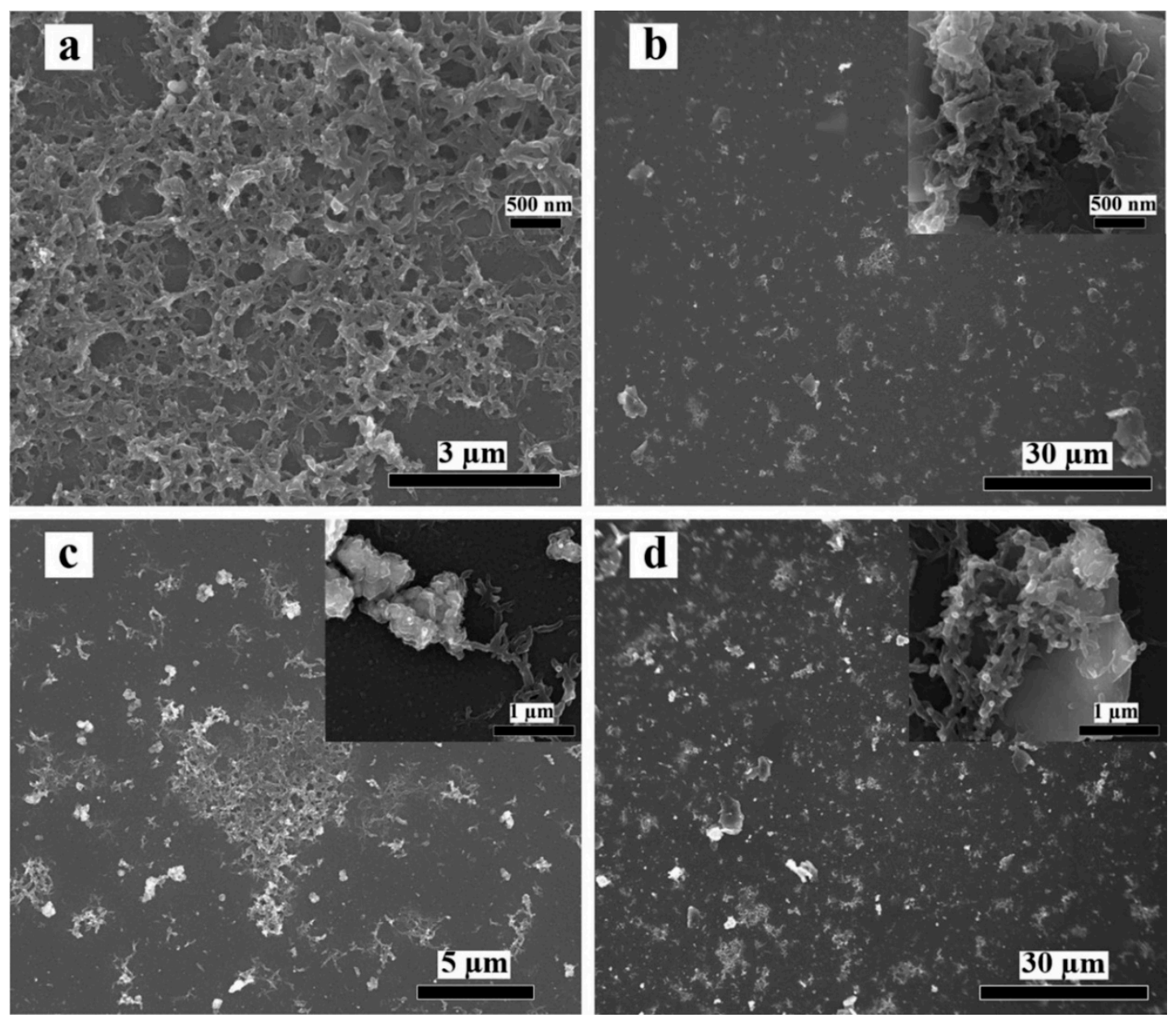

Figure 3. SEM images of (a) pristine PANI film, (b) graphene/PANI film, (c) $\mathrm{WO}_{3} / \mathrm{PANI}$ film, and (d) $\mathrm{WO}_{3}$ /graphene/PANI film. Inset is the magnification of corresponding SEM image.

\subsection{Electrochromic Behaviors}

Figure 4 shows the UV-vis transmission spectra of (A) pure $\mathrm{WO}_{3}$ film, (B) double layer $\mathrm{WO}_{3} /$ graphene film, (C) pristine PANI film, (D) double layer graphene/PANI film, (E) double layer $\mathrm{WO}_{3} / \mathrm{PANI}$ film, and (F) triple layer $\mathrm{WO}_{3} /$ graphene/PANI film at different potentials $(-0.5,-0.2,0.3$ and $0.8 \mathrm{~V})$ in $0.5 \mathrm{M} \mathrm{H}_{2} \mathrm{SO}_{4}$, respectively. For all the PANI-based nanocomposites with applied potential from -0.5 to $0.8 \mathrm{~V}$ (Figure 4C-F) similar UV-vis spectra can be clearly observed as the transmittance decreases continuously with the increasing potential, indicating the promoted oxidation of PANI. In addition, the characteristic absorbance band from 500 to $750 \mathrm{~nm}$ belongs to the emeraldine salt form in PANI resulting from the $\pi-\pi^{*}$ transition of the quinoid ring, especially for the highly oxidized state at $0.8 \mathrm{~V}$, implying the dominant role of PANI in the hybrid PANI-based films [44]. For bare $\mathrm{WO}_{3}$ film, Figure $4 \mathrm{~A}$ shows that the transmittance keeps constant with varying the potential because of the small amount of $\mathrm{WO}_{3}$ and the narrow potential range of $\mathrm{WO}_{3}$. The transmittance of double layer $\mathrm{WO}_{3} /$ graphene film exhibits small increased transmittance values with increasing potential from $-0.2-0.8 \mathrm{~V}$, which can be attributed to the altered electronic structure of the introduced graphene. However, it is noticeable that the transmittance values decrease largely after the introduction of graphene into $\mathrm{WO}_{3}$ film compared with that of bare $\mathrm{WO}_{3}$ film, which can be ascribed to the block role of graphene. Similar phenomenon is also observed in Figure 4D after introducing graphene into the pristine PANI film, the transmittance values at different potentials remain almost the same with slightly decreasing trend because of the light block effect of graphene. However, no obvious difference was observed in Figure $4 \mathrm{E}$ for $\mathrm{WO}_{3} / \mathrm{PANI}$ film compared with that of pristine PANI film. Finally, it is clearly seen from Figure $4 \mathrm{~F}$ that all the 
transmittance values of the triple layer $\mathrm{WO}_{3} /$ graphene/PANI film are relatively low $(\sim 15 \%)$ because of the introduced graphene. However, the film also exhibits obvious decreased transmittance values and typical PANI peaks with the increasing potentials.
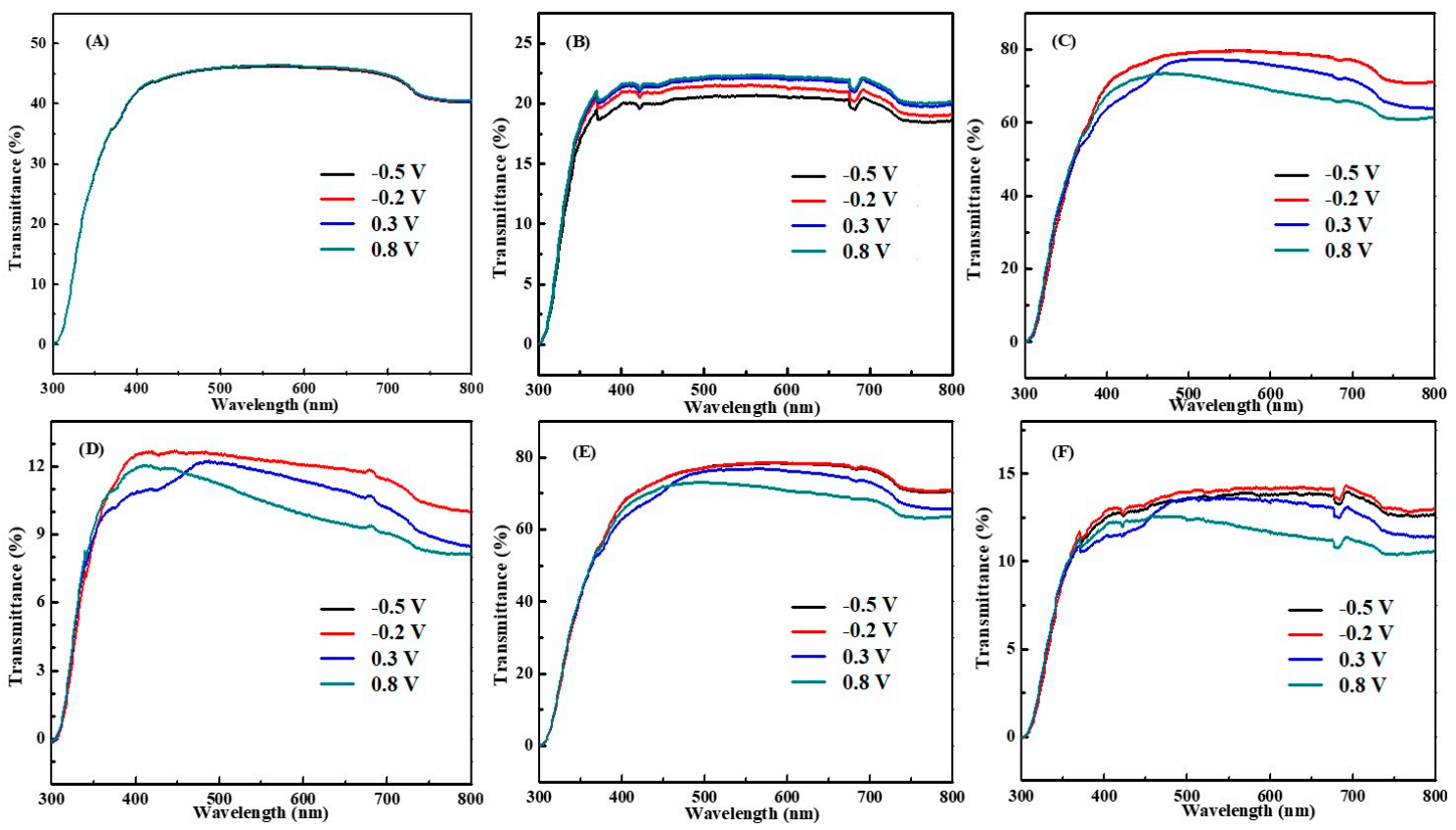

Figure 4. UV-vis spectra of (A) pure $\mathrm{WO}_{3}$ film, (B) double layer $\mathrm{WO}_{3} /$ graphene film, (C) pristine PANI film, (D) double layer graphene/PANI film, (E) double layer $\mathrm{WO}_{3} / \mathrm{PANI}$ film, and (F) triple layer $\mathrm{WO}_{3}$ /graphene/PANI film in $0.5 \mathrm{M} \mathrm{H}_{2} \mathrm{SO}_{4}$ aqueous solution at different potentials as $-0.5,-0.2,0.3$, and $0.8 \mathrm{~V}$.

The coloration switching responses as an important parameter is vital to evaluate the electrochromic performance in terms of energy consumption and coloration switching. The coloration properties of all the PANI-based nanocomposites films were studied by applying potential steps of 0.8 and $-0.2 \mathrm{~V}$ with a pulse width of $20 \mathrm{~s}$. Figure $5 \mathrm{a}-\mathrm{d}$ shows the transmittance-time (red) and the corresponding charge density-time curves (black) at $633 \mathrm{~nm}$ under an alternative square-wave voltage of 0.8 and $-0.2 \mathrm{~V}$ with $20 \mathrm{~s}$ interval. The transmittance modulations, transmittance difference between the bleached and colored states in the electrochromic materials, as $6.12,1.71,9.04$, and $4.52 \%$ are calculated for the pristine PANI, double layer graphene/PANI, double layer $\mathrm{WO}_{3} / \mathrm{PANI}$, and triple layer $\mathrm{WO}_{3} /$ graphene/PANI nanocomposites films, respectively. Decreased transmittance modulations of graphene contained films confirm further the block effect of the introduced graphene.
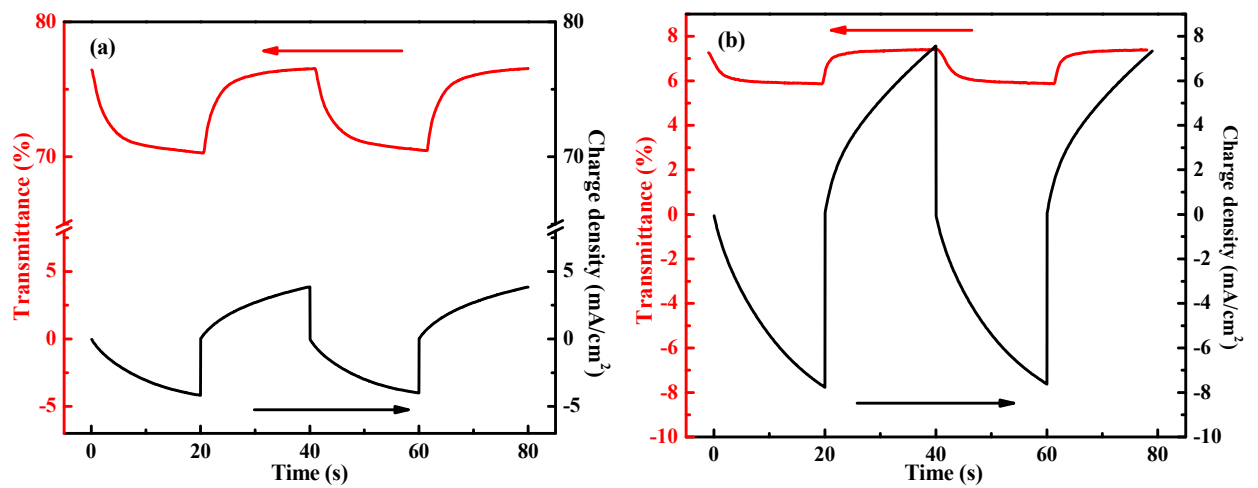

Figure 5. Cont. 

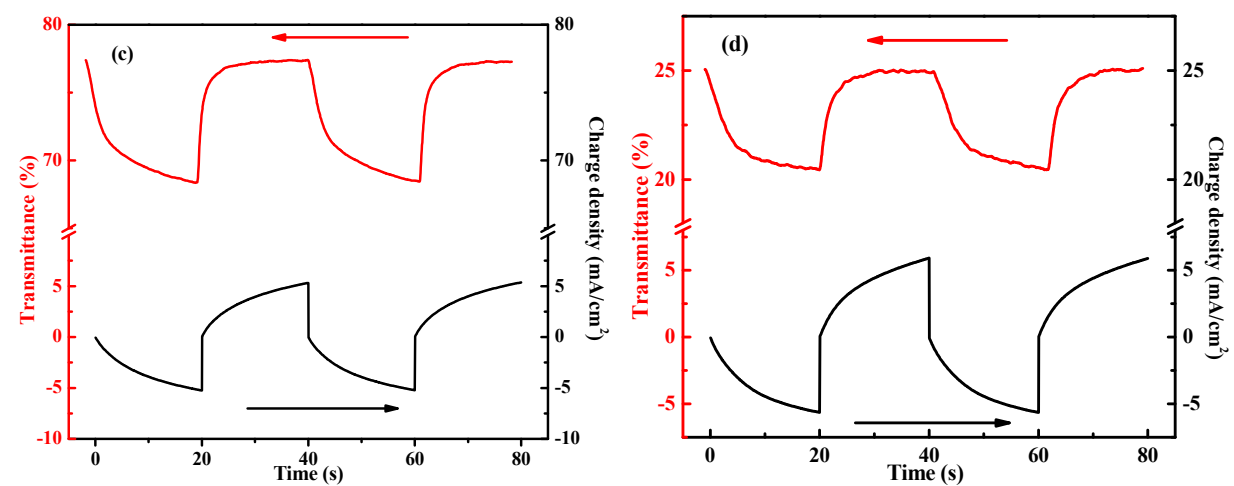

Figure 5. In situ transmittance (red) and corresponding chronocoulometry (black) of (a) pristine PANI film, (b) graphene/PANI film, (c) $\mathrm{WO}_{3} / \mathrm{PANI}$ film, and (d) $\mathrm{WO}_{3} /$ graphene/PANI film at $633 \mathrm{~nm}$ in $0.5 \mathrm{M}$ $\mathrm{H}_{2} \mathrm{SO}_{4}$ aqueous solution. The tests were conducted under a square-wave voltage of 0.8 and $-0.2 \mathrm{~V}$ with a pulse width of $20 \mathrm{~s}$.

Coloration efficiency (CE or $\eta$ ) is a critical parameter of electrochromic materials for practical applications. It is defined as the change in the optical density (OD) per unit charge (Q) inserted into (or extracted from) the electrochromic films, that is, the amount of energy to achieve color change. The CE is calculated from Equations (2) and (3):

$$
\begin{gathered}
\eta=\Delta O D(\lambda) / Q_{d} \\
\Delta O D=\log \left[T_{\text {colored }} / T_{\text {bleached }}\right]
\end{gathered}
$$

where $\triangle O D$ is the change in the optical density, $\lambda$ is the dominant wavelength for the material, $Q_{d}$ is the charge density (injected/ejected charges per unit electrode area), $T_{\text {beleached }}$ refers to the transmittance of the film in the bleached state, and $T_{\text {colored }}$ refers to the varying transmittance of the film during the coloring process. Figure 6 depicts the plots of the calculated $\triangle O D$ from the second cycle in the transmittance-time curve at $633 \mathrm{~nm}$ versus the corresponding inserted charge density obtained from charge density-time curve (Figure 5). The $\eta$ is extracted as the slope of the straight line fitting to the linear region of the curve. The $\eta$ values of composite films are all found to be larger than that of pristine PANI and increasing follow an order as graphene/PANI $>\mathrm{WO}_{3} /$ graphene/PANI $>\mathrm{WO}_{3} / \mathrm{PANI}$ $>$ pristine PANI. The improved CE for the PANI-based nanocomposites films indicate an enhanced color changing response ability as fewer injected charges result in larger optical density change than that of the pristine PANI film. The films with graphene exhibit a greatly increased $\eta$ due to the largely decreased resistance and properly formed matrix structure. Furthermore, the enhanced $\eta$ value of $\mathrm{WO}_{3} /$ graphene can be attributed to the resulted porous nanostructures from the $\mathrm{WO}_{3}$ embedment.

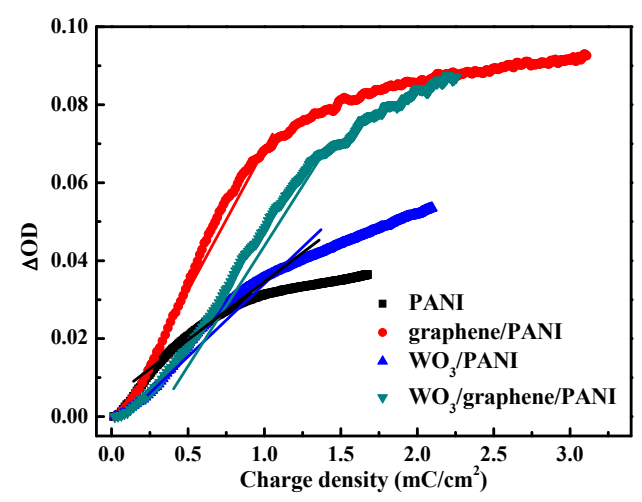

Figure 6. The plots of in situ optical density $(\triangle \mathrm{OD})$ versus charge density of pristine PANI film, graphene/PANI film, $\mathrm{WO}_{3} / \mathrm{PANI}$ film, and $\mathrm{WO}_{3} /$ graphene/PANI films. The optical density was measured at $633 \mathrm{~nm}$ at $0.8 \mathrm{~V}$ in $0.5 \mathrm{M} \mathrm{H}_{2} \mathrm{SO}_{4}$ aqueous solution. 


\subsection{Capacitive Energy Storage Performances}

The capacitive performances of the different films were studied by cyclic voltammogram $(\mathrm{CV})$ at a high scan rate of $50 \mathrm{mV} / \mathrm{s}$ within a potential range of -0.2 to $0.8 \mathrm{~V}$ in $0.5 \mathrm{M} \mathrm{H}_{2} \mathrm{SO}_{4}$ as shown in Figure 7A. The CV curves of the PANI-based nanocomposites films at other scan rates $(100,20$, and $5 \mathrm{mV} / \mathrm{s})$ are also provided in Figure S2. Higher current densities with larger enclosed CV areas are clearly seen in $\mathrm{WO}_{3} /$ graphene/PANI, followed by graphene/PANI, $\mathrm{WO}_{3} / \mathrm{PANI}$, pristine $\mathrm{PANI}, \mathrm{WO}_{3} /$ graphene, and bare $\mathrm{WO}_{3}$, indicating more energy stored in the PANI-based films after introducing the corresponding nanofillers because of the increased PANI amount and the capacitance contributions of the nanofillers. Furthermore, Figure 7A shows that all the PANI-based nanocomposites exhibit nonrectangular CV curves with obvious one pair of redox peaks around $0.4 / 0.3 \mathrm{~V}$, which are characteristic peaks of PANI oxidation and reduction. However, it is also noted that the oxidation peaks have slight shift because of the embedment of the nanofillers, which confirms the proper interactions between PANI matrix and nanofillers. Obviously, the $\mathrm{WO}_{3}$ /graphene/PANI exhibits a much higher current density than other film counterparts, suggesting that $\mathrm{WO}_{3} /$ graphene/PANI film is the most promising one for supercapacitor application among all the samples.
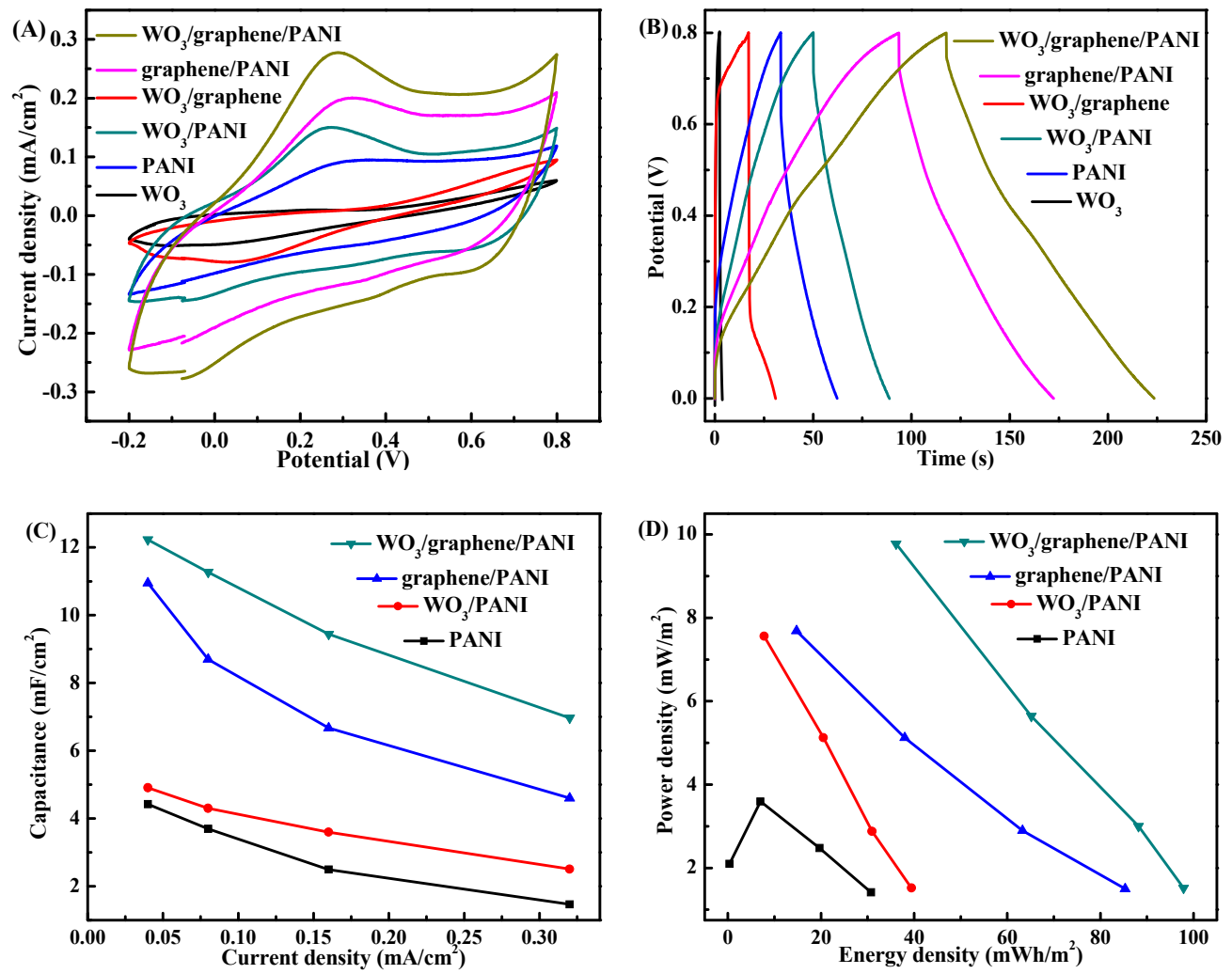

Figure 7. (A) CVs conducted at a scan rate of $50 \mathrm{mV} / \mathrm{s}$, (B) charge-discharge curves with a current density of $0.08 \mathrm{~mA} / \mathrm{cm}^{2},(\mathbf{C})$ specific capacitances depended on current density, and (D) Ragone plots of bare $\mathrm{WO}_{3}$ film, double layer $\mathrm{WO}_{3}$ /graphene film, pristine PANI film, double layer $\mathrm{WO}_{3} / \mathrm{PANI}$ film, double layer graphene/PANI film, and triple layer $\mathrm{WO}_{3} /$ graphene/PANI film measured in $0.5 \mathrm{M} \mathrm{H}_{2} \mathrm{SO}_{4}$ aqueous solution.

Galvanostatic charge-discharge (GCD) as a reliable approach to measure the specific capacitance of supercapacitor is also carried out in the same $\mathrm{H}_{2} \mathrm{SO}_{4}$ solution from 0 to $0.8 \mathrm{~V}$ with a current density of $0.08 \mathrm{~mA} / \mathrm{cm}^{2}$, as shown in Figure 7B. All the GCD curves of PANI-based nanocomposites exhibit non-straight lines because of the dominant pseudo-capacitor role of PANI. The increasing discharging time always represents a higher capacitance. It is observed that the capacitance of the pristine PANI film can be greatly enhanced through introducing $\mathrm{WO}_{3}$ and graphene nanofillers, confirmed by the 
discharging time order as pristine $\mathrm{PANI}<\mathrm{WO}_{3} / \mathrm{PANI}<$ graphene $/ \mathrm{PANI}<\mathrm{WO}_{3} /$ graphene/PANI, which is also in good accordance with the area of $\mathrm{CV}$ results. In addition, the voltage drop at the initiation of the discharge curve is extremely small for $\mathrm{WO}_{3}$ /graphene/PANI among all the films, indicating a very low equivalent series resistance (ESR) in the supercapacitor and also enables high-power operations. The specific capacitances of different films calculated from the CV at $50 \mathrm{mV} / \mathrm{s}$ and the GCD at $0.08 \mathrm{~mA} / \mathrm{cm}^{2}$ are summarized in Table 1 , which follow the same order as $\mathrm{WO}_{3} /$ graphene/PANI $>$ graphene/PANI $>$ $\mathrm{WO}_{3} / \mathrm{PANI}>$ pristine $\mathrm{PANI}>\mathrm{WO}_{3} /$ graphene $>$ bare $\mathrm{WO}_{3}$, confirming the positive effects of graphene and $\mathrm{WO}_{3}$. Furthermore, the correlation between the specific capacitance and the current density for these four PANI-based films is also presented in Figure 7C. The $\mathrm{WO}_{3} /$ graphene/PANI has the highest capacity among all samples at all the same scan rates. For instance, the $\mathrm{WO}_{3} /$ graphene/PANI achieves a specific capacitance of $11.267 \mathrm{mF} / \mathrm{cm}^{2}$ with $0.08 \mathrm{~mA} / \mathrm{cm}^{2}$ current density, which is 1.3 and 2.6 times higher than that of graphene/PANI $\left(8.709 \mathrm{mF} / \mathrm{cm}^{2}\right)$ and $W_{3} / \mathrm{PANI}\left(4.312 \mathrm{mF} / \mathrm{cm}^{2}\right)$, respectively. Notably, $\mathrm{WO}_{3} /$ graphene/PANI shows capacitance three times larger than that of pristine PANI $\left(3.693 \mathrm{mF} / \mathrm{cm}^{2}\right)$, indicating a dramatic capacitance increasement when employing graphene and $\mathrm{WO}_{3}$ nanofillers. Furthermore, the triple layer $\mathrm{WO}_{3} /$ graphene/PANI film shows a capacity of 12.27 and $7.017 \mathrm{~F} / \mathrm{g}$ with 0.04 and $0.32 \mathrm{~mA} / \mathrm{cm}^{2}$ current density, respectively, suggesting a considerable rate capability of $\mathrm{WO}_{3} /$ graphene/PANI. The improvement in power density of $\mathrm{WO}_{3}$ /graphene/PANI is further confirmed by the Ragone plots of these four PANI-based films as shown in Figure 7D. Similar power density trend was clearly observed as $\mathrm{WO}_{3} /$ graphene/PANI $>$ graphene/PANI $>\mathrm{WO}_{3} / \mathrm{PANI}>$ pristine PANI as a function of energy density. Furthermore, the as-developed $\mathrm{WO}_{3} /$ graphene/PANI can outperform a lot of reported mass-based values in terms of capacitance and energy density [23,31,32]. It is noted that, besides the appealing electrochemical properties as supercapacitor, this facile prepared $\mathrm{WO}_{3} /$ graphene/PANI film may also show considerable performances regarding PANI related practical applications like chemical vapor sensors, transparent conductors, and actuators.

Table 1. Summary of capacitance, energy density, and power density values of the different films calculated for cyclic voltammogram (CV) and galvanostatic charge-discharge (GCD) results (Calculation methods shown in supporting materials).

\begin{tabular}{|c|c|c|c|c|}
\hline Film & $\begin{array}{c}\mathrm{CV} \mathrm{C}_{S} . \\
50 \mathrm{mV} / \mathrm{s} \\
\left(\mathrm{mF} \mathrm{cm}^{-2}\right)\end{array}$ & $\begin{array}{c}\text { GCD Cs. } \\
0.08 \mathrm{~mA} / \mathrm{cm}^{2} \\
\left(\mathrm{mF} \mathrm{cm}^{-2}\right)\end{array}$ & $\begin{array}{c}\text { Energy } \\
\text { Density } \\
\left(\mathrm{mWh} / \mathrm{m}^{2}\right)\end{array}$ & $\begin{array}{c}\text { Power } \\
\text { Density } \\
\left(\mathrm{mW} / \mathrm{m}^{2}\right)\end{array}$ \\
\hline $\mathrm{WO}_{3}$ & 0.489 & 0.253 & 0.688 & 1.770 \\
\hline $\mathrm{WO}_{3} /$ graphene & 0.764 & 2.586 & 6.360 & 1.683 \\
\hline PANI & 1.371 & 3.693 & 19.69 & 2.478 \\
\hline $\mathrm{WO}_{3} / \mathrm{PANI}$ & 1.856 & 4.312 & 30.95 & 2.879 \\
\hline graphene/PANI & 2.629 & 8.709 & 63.29 & 2.895 \\
\hline $\mathrm{WO}_{3} /$ graphene/PANI & 3.414 & 11.267 & 88.17 & 3.003 \\
\hline
\end{tabular}

Electrochemical impedance spectroscopy (EIS) as a power technique probing the inherent reaction kinetics of the electrode was also employed as shown in Figure 8. The semicircular Nyquist plots of imaginary $\left(Z^{\prime \prime}, \Omega\right)$ versus real $\left(Z^{\prime}, \Omega\right)$ components of impedance were conducted in the frequency range of 100,000 to $0.01 \mathrm{~Hz}$ with a $5 \mathrm{mV}$ amplitude referring to open potential in $0.5 \mathrm{M} \mathrm{H}_{2} \mathrm{SO}_{4}$. It is clearly seen that the resistance of bare $\mathrm{WO}_{3}$ film is larger than the others throughout the mostly frequency region due to the low conductivity of $\mathrm{WO}_{3}$. Meanwhile, the decreased resistance of $\mathrm{WO}_{3} / \mathrm{PANI}$ and $\mathrm{WO}_{3} /$ graphene results from the introduced highly conductive PANI and graphene, respectively. However, no resistor-capacitor (RC) loops or semicircles appear in the high frequency region for PANI-based films, indicating negligible charge resistances and the better energy storage properties of the PANI-based films. The excellent energy storage performance of $\mathrm{WO}_{3} /$ graphene/PANI can be clearly demonstrated as the tail approaching an almost vertical line compared with others. In addition, the equivalent series resistance (ESR) of each sample can be calculated from the $Z^{\prime}$ values at $Z^{\prime \prime}=0$, which has been shown in Table S1. The resistivity of the films follows the order as $\mathrm{WO}_{3} /$ graphene/PANI < 
graphene/PANI $<\mathrm{WO}_{3} /$ graphene $<$ pristine PANI $<\mathrm{WO}_{3} / \mathrm{PANI}<\mathrm{WO}_{3}$, demonstrating enhanced reaction kinetics because of the positive effects of graphene and $\mathrm{WO}_{3}$ nanofillers, which is also consist with the CV and GCD analysis.

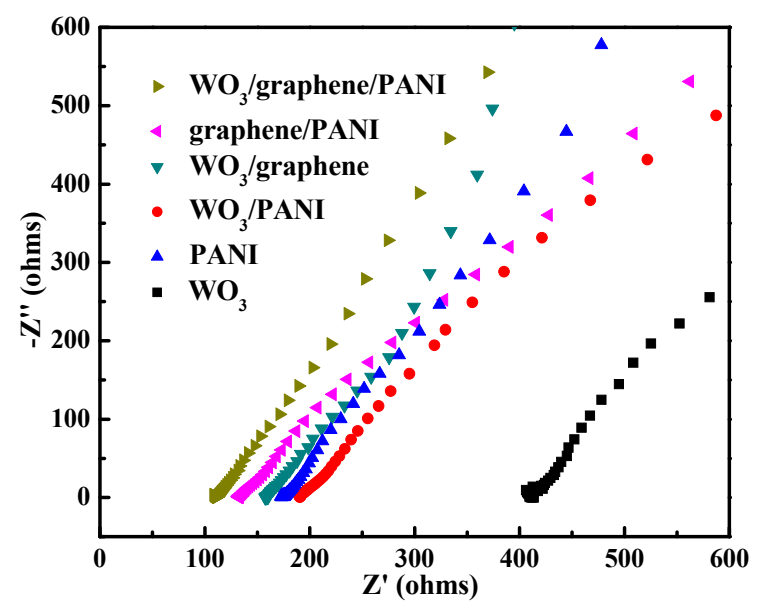

Figure 8. Nyquist plots of bare $\mathrm{WO}_{3}, \mathrm{WO}_{3} /$ graphene, pristine $\mathrm{PANI}, \mathrm{WO}_{3} / \mathrm{PANI}$, graphene/PANI, and $\mathrm{WO}_{3} /$ graphene/PANI films in $0.5 \mathrm{M} \mathrm{H}_{2} \mathrm{SO}_{4}$ aqueous solution, respectively.

\subsection{Cycling Stability}

Since a long cycling performance is of the most important criteria for supercapacitors, the cycling performances of these four PANI-based films were conducted by GCD for 1200 cycles with a current density of $0.16 \mathrm{~mA} / \mathrm{cm}^{2}$. The cycling performances with specific capacitance retention are shown in Figure 9. It is clearly seen that all the PANI-based nanocomposites films exhibit much better cycling performance than that of pristine PANI. For example, the graphene/PANI has an $80 \%$ retention, higher than that of pristine PANI (70\%), indicating the positive role of graphene which is also consistent with reported works [45,46]. However, both the $\mathrm{WO}_{3} /$ graphene and $\mathrm{WO}_{3} /$ graphene/PANI electrodes have slight capacitance increases during the cycling process. The capacitance increases can be attributed to the introduced $\mathrm{WO}_{3}$ nanoparticles, which were increasingly accessed along with cycling. The $\mathrm{WO}_{3}$ particles used in this work have a nanoscale size around 40-50 nm, indicating a high specific surface area of the nanoparticles. Therefore, a combined electric double-layer capacitance from high surface area and pseudo-capacitor capacitance from redox reactions can be delivered by $\mathrm{WO}_{3}$ nanoparticles. Accompanied by the charge-discharge cycles, the activation and volume change of $\mathrm{WO}_{3}$ nanoparticles lead to higher pseudo-capacitor capacitance from more redox active sites, that is, enhanced capacitance during cycling. The cycling performance of the as-prepared PANI films follows the order as $\mathrm{WO}_{3} / \mathrm{PANI}$ $>\mathrm{WO}_{3} /$ graphene/PANI $>$ graphene/PANI $>$ pristine PANI, which implies the $\mathrm{WO}_{3} /$ graphene/PANI film is capable to serve as a promising supercapacitor material because of its much-enhanced capacitance and cycling performance. The above results clearly reveal the potential applications of this triple layer $\mathrm{WO}_{3}$ /graphene/PANI for supercapacitors, while also highlighting again the positive effects of $\mathrm{WO}_{3}$ and graphene nanofillers on the PANI matrix. 


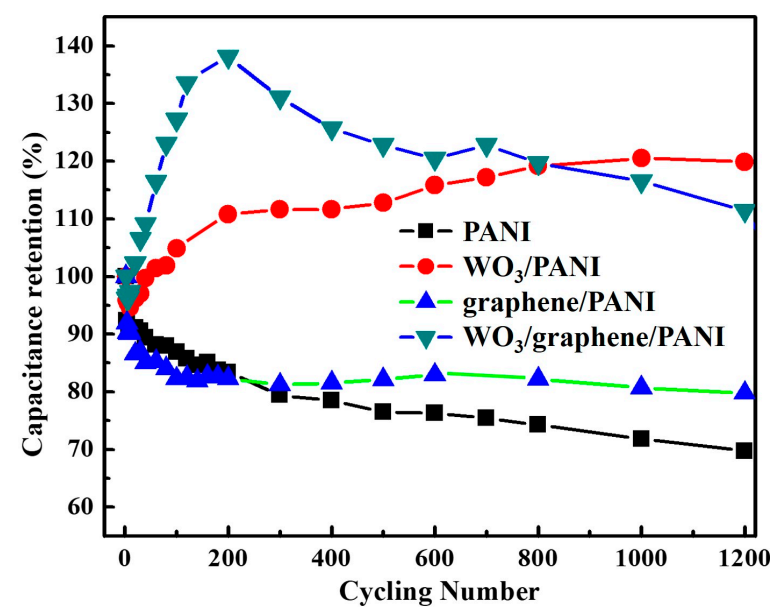

Figure 9. Cycling stability of pristine PANI, $\mathrm{WO}_{3} / \mathrm{PANI}$, graphene/PANI, and $\mathrm{WO}_{3} /$ graphene/PANI film electrodes at $0.16 \mathrm{~mA} / \mathrm{cm}^{2}$ for 1200 cycles in $0.5 \mathrm{M} \mathrm{H}_{2} \mathrm{SO}_{4}$ aqueous solution.

\section{Conclusions}

Different hybrid $\mathrm{WO}_{3}$, graphene, and PANI films have been successfully prepared by electrodepositing PANI monomers onto pre-spincoated $\mathrm{WO}_{3}$, graphene, and $\mathrm{WO}_{3}$ /graphene ITO glasses. Multi-color electrochromic phenomenon and supercapacitive performance of the different PANI films have been observed in this nanocomposite film owing to the dominant PANI component in the composites. Higher coloration efficiency and faster switching responses of the PANI-based nanocomposites films than those of the pristine PANI film are obtained from the inner interactions between the PANI matrix and the nanofillers, as well as the resulted rougher morphology. However, the introduced graphene can decease the light transmittance modulation of the PANI-based films because of its light block effect. The PANI-based nanocomposites films also exhibit enhanced areal capacitances compared to that of the pristine PANI film because of the capacitive role of nanofillers and the increased deposition amount of PANI materials. Largely enhanced cycling stabilities were also obtained because of the positive effects of graphene and $\mathrm{WO}_{3}$. In summary, this novel triple layer $\mathrm{WO}_{3} /$ graphene/PANI nanocomposites film, incorporating the advantages of both graphene and $\mathrm{WO}_{3}$ in PANI matrix, has exhibited promising application potential in devices integrated the functions of both electrochromic and energy storage because of its considerable electrochromic and capacitive behaviors.

Supplementary Materials: The following are available online at http://www.mdpi.com/2073-4360/12/1/49/s1. Figure S1: AFM images of (a) bare $\mathrm{WO}_{3}$ film, (b) double layer $\mathrm{WO}_{3} /$ graphene film, (c) pristine PANI film, (d) double layer graphene/PANI film, (e) double layer $\mathrm{WO}_{3} / \mathrm{PANI}$ film, and (f) triple layer $\mathrm{WO}_{3} /$ graphene/PANI film. Below of each is the height profile of the corresponding film. Figure S2: CV (A, C, E, and G) and GCD (B, D, $\mathbf{F}$, and $\mathbf{H}$ ) curves of $(\mathrm{A}$ and $\mathrm{B})$ pristine PANI, $\left(\mathrm{C}\right.$ and D) $\mathrm{WO}_{3} / \mathrm{PANI},(\mathrm{E}$ and $\mathrm{F})$ graphene/PANI, and $(\mathrm{G}$ and $\mathrm{H})$ $\mathrm{WO}_{3}$ /graphene/PANI in $0.5 \mathrm{M} \mathrm{H}_{2} \mathrm{SO}_{4}$ with different $\mathrm{CV}$ scan rates as (a) 100, (b) 50, (c) 20, and (d) $5 \mathrm{mV} / \mathrm{s}$ and different GCD current densities as (a) 0.32 , (b) 0.16 , (c) 0.08 , and (d) $0.04 \mathrm{~mA} / \mathrm{cm}^{2}$. Table S1: The equivalent series resistance (ESR) values of the different films calculated from the Nyquist plots.

Funding: This research received no external funding.

Acknowledgments: The financial supports from University of Tennessee Knoxville are kindly acknowledged.

Conflicts of Interest: The authors declare no conflict of interest.

\section{References}

1. Lyu, H.; Li, Y.; Jafta, C.J.; Bridges, C.A.; Meyer, H.M., III; Borisevich, A.; Paranthaman, M.P.; Dai, S.; Sun, X.-G. Bis (trimethylsilyl) 2-fluoromalonate derivatives as electrolyte additives for high voltage lithium ion batteries. J. Power Sources 2019, 412, 527-535. [CrossRef] 
2. Zhang, L.; Zhang, Q.; Xie, H.; Guo, J.; Lyu, H.; Li, Y.; Sun, Z.; Wang, H.; Guo, Z. Electrospun titania nanofibers segregated by graphene oxide for improved visible light photocatalysis. Appl. Catal. B Environ. 2017, 201, 470-478. [CrossRef]

3. Liu, J.; Guo, S.; Hu, C.; Lyu, H.; Yan, X.; Guo, Z. Advanced Nanocomposite Electrodes for Lithium-Ion Batteries. Multifunct. Nanocomposites Energy Environ. Appl. 2018, 1, 7-32.

4. Lyu, H.; Liu, J.; Qiu, S.; Cao, Y.; Hu, C.; Guo, S.; Guo, Z. Carbon composite spun fibers with in situ formed multicomponent nanoparticles for a lithium-ion battery anode with enhanced performance. J. Mater. Chem. A 2016, 4, 9881-9889. [CrossRef]

5. Hu, C.; Qiu, S.; Lu, G.; Cao, H.; Lv, H.; Guo, S.; Liu, J. Enhanced electrochemical performance of barium hexaferrite nanoplates by $\mathrm{Zn} 2+$ doping serving as anode materials. Rsc. Adv. 2015, 5, 70749-70757. [CrossRef]

6. Wang, G.; Zhang, L.; Zhang, J. A review of electrode materials for electrochemical supercapacitors. Chem. Soc. Rev. 2012, 41, 797-828. [CrossRef]

7. Lyu, H.; Jafta, C.J.; Popovs, I.; Meyer, H.M.; Hachtel, J.A.; Huang, J.; Sumpter, B.G.; Dai, S.; Sun, X.-G. A dicyanobenzoquinone based cathode material for rechargeable lithium and sodium ion batteries. J. Mater. Chem. A 2019, 7, 17888-17895. [CrossRef]

8. Kung, C.-W.; Wang, T.C.; Mondloch, J.E.; Fairen-Jimenez, D.; Gardner, D.M.; Bury, W.; Klingsporn, J.M.; Barnes, J.C.; van Duyne, R.; Stoddart, J.F.; et al. Metal-organic framework thin films composed of free-standing acicular nanorods exhibiting reversible electrochromism. Chem. Mater. 2013, 25, 5012-5017. [CrossRef]

9. Monk, P.; Mortimer, R.; Rosseinsky, D. Electrochromism and Electrochromic Devices; Cambridge University Press: Cambridge, UK, 2007.

10. Scherer, M.R.J.; Li, L.; Cunha, P.M.S.; Scherman, O.A.; Steiner, U. Enhanced Electrochromism in Gyroid-Structured Vanadium Pentoxide. Adv. Mater. 2012, 24, 1217-1221. [CrossRef]

11. Heuer, H.W.; Wehrmann, R.; Kirchmeyer, S. Electrochromic Window Based on Conducting Poly (3, 4-ethylenedioxythiophene)-Poly (styrene sulfonate). Adv. Funct. Mater. 2002, 12, 89-94. [CrossRef]

12. Wu, N.; Lv, H.; Liu, J.; Liu, Y.; Wang, S.; Liu, W. Improved electromagnetic wave absorption of Co nanoparticles decorated carbon nanotubes derived from synergistic magnetic and dielectric losses. Phys. Chem. Chem. Phys. 2016, 18, 31542-31550. [CrossRef]

13. Qiu, S.; Lyu, H.; Liu, J.; Liu, Y.; Wu, N.; Liu, W. Facile synthesis of porous nickel/carbon composite microspheres with enhanced electromagnetic wave absorption by magnetic and dielectric losses. Acs Appl. Mater. Interfaces 2016, 8, 20258-20266. [CrossRef]

14. Lin, F.; Nordlund, D.; Weng, T.-C.; Sokaras, D.; Jones, K.M.; Reed, R.B.; Gillaspie, D.T.; Weir, D.G.J.; Moore, R.G.; Dillon, A.C.; et al. Origin of electrochromism in high-performing nanocomposite nickel oxide. ACS Appl. Mater. Interfaces 2013, 5, 3643-3649. [CrossRef]

15. Beaujuge, P.M.; Reynolds, J.R. Color control in $\pi$-conjugated organic polymers for use in electrochromic devices. Chem. Rev. 2010, 110, 268-320. [CrossRef]

16. Thakur, V.K.; Ding, G.; Ma, J.; Lee, P.S.; Lu, X. Hybrid materials and polymer electrolytes for electrochromic device applications. Adv. Mater. 2012, 24, 4071-4096. [CrossRef]

17. Hu, C.; Cao, H.; Wang, S.; Wu, N.; Qiu, S.; Lyu, H.; Liu, J. Synthesis of strontium hexaferrite nanoplates and the enhancement of their electrochemical performance by $\mathrm{Zn} 2+$ doping for high-rate and long-life lithium-ion batteries. New J. Chem. 2017, 41, 6427-6435. [CrossRef]

18. Wang, K.; Wu, H.; Meng, Y.; Zhang, Y.; Wei, Z. Integrated energy storage and electrochromic function in one flexible device: An energy storage smart window. Energy Environ. Sci. 2012, 5, 8384-8389. [CrossRef]

19. Olinga, T.E.; Fraysse, J.; Travers, J.P.; Dufresne, A.; Pron, A. Highly conducting and solution-processable polyaniline obtained via protonation with a new sulfonic acid containing plasticizing functional groups. Macromolecules 2000, 33, 2107-2113. [CrossRef]

20. Lyu, H.; Liu, J.; Mahurin, S.; Dai, S.; Guo, Z.; Sun, X.-G. Polythiophene coated aromatic polyimide enabled ultrafast and sustainable lithium ion batteries. J. Mater. Chem. A 2017, 5, 24083-24092. [CrossRef]

21. Bhadra, S.; Khastgir, D.; Singha, N.K.; Lee, J.H. Progress in preparation, processing and applications of polyaniline. Prog. Polym. Sci. 2009, 34, 783-810. [CrossRef]

22. Bhadra, S.; Singha, N.K.; Khastgir, D. Electrochemical synthesis of polyaniline and its comparison with chemically synthesized polyaniline. J. Appl. Polym. Sci. 2007, 104, 1900-1904. [CrossRef] 
23. Jang, J.; Oh, J.H. Fabrication of a highly transparent conductive thin film from polypyrrole/poly (methyl methacrylate) core/shell nanospheres. Adv. Funct. Mater. 2005, 15, 494-502. [CrossRef]

24. Unur, E.; Jung, J.-H.; Mortimer, R.J.; Reynolds, J.R. Dual-polymer electrochromic film characterization using bipotentiostatic control. Chem. Mater. 2008, 20, 2328-2334. [CrossRef]

25. Matsui, J.; Kikuchi, R.; Miyashita, T. A trilayer film approach to multicolor electrochromism. J. Am. Chem. Soc. 2014, 136, 842-845. [CrossRef]

26. Tseng, C.-Y.; Hu, C.-W.; Huang, K.-C.; Chang, L.-C.; Vittal, R.; Ho, K.-C. Ion transport across the film of poly(5,6-dimethoxyindole-2-carboxylic acid) in relation to its electrochromic switching: An electrochemical quartz crystal microbalance study. Electrochim. Acta 2013, 101, 232-237. [CrossRef]

27. Yoon, S.; Kang, E.; Kim, J.K.; Lee, C.W.; Lee, J. Development of high-performance supercapacitor electrodes using novel ordered mesoporous tungsten oxide materials with high electrical conductivity. Chem. Commun. 2011, 47, 1021-1023. [CrossRef]

28. Jo, C.; Hwang, J.; Song, H.; Dao, A.H.; Kim, Y.-T.; Lee, S.H.; Hong, S.W.; Yoon, S.; Lee, J. Block-Copolymer-Assisted One-Pot Synthesis of Ordered Mesoporous $\mathrm{WO}_{3-\mathrm{x}} /$ Carbon Nanocomposites as High-Rate-Performance Electrodes for Pseudocapacitors. Adv. Funct. Mater. 2013, 23, 3747-3754. [CrossRef]

29. Fu, Y.; Gu, H.; Yan, X.; Liu, J.; Wang, Y.; Huang, J.; Li, X.; Lv, H.; Wang, X.; Guo, J.; et al. Chromium (III) oxide carbon nanocomposites lithium-ion battery anodes with enhanced energy conversion performance. Chem. Eng. J. 2015, 277, 186-193. [CrossRef]

30. Wen, R.-T.; Niklasson, G.A.; Granqvist, C.G. Sustainable Rejuvenation of Electrochromic $\mathrm{WO}_{3}$ Films. Acs Appl. Mater. Interfaces 2015, 7, 28100-28104. [CrossRef]

31. Shen, K.; Ran, F.; Tan, Y.; Niu, X.; Fan, H.; Yan, K.; Kong, L.; Kang, L. Toward interconnected hierarchical porous structure via chemical depositing organic nano-polyaniline on inorganic carbon scaffold for supercapacitor. Synth. Met. 2015, 199, 205-213. [CrossRef]

32. Jeon, J.-W.; Kwon, S.R.; Li, F.; Lutkenhaus, J.L. Spray-on polyaniline/poly (acrylic acid) electrodes with enhanced electrochemical stability. Acs Appl. Mater. Interfaces 2015, 7, 24150-24158. [CrossRef] [PubMed]

33. Yan, J.; Wei, T.; Fan, Z.; Qian, W.; Zhang, M.; Shen, X.; Wei, F. Preparation of graphene nanosheet/carbon nanotube/polyaniline composite as electrode material for supercapacitors. J. Power Sources 2010, 195, 3041-3045. [CrossRef]

34. Lv, H.; Qiu, S.; Lu, G.; Fu, Y.; Li, X.; Hu, C.; Liu, J. Nanostructured antimony/carbon composite fibers as anode material for lithium-ion battery. Electrochim. Acta 2015, 151, 214-221. [CrossRef]

35. Li, X.; Gu, H.; Liu, J.; Wei, H.; Qiu, S.; Fu, Y.; Lv, H.; Lu, G.; Wang, Y.; Guo, Z. Multi-walled carbon nanotubes composited with nanomagnetite for anodes in lithium ion batteries. RSC Adv. 2015, 5, 7237-7244. [CrossRef]

36. Lu, G.; Qiu, S.; Lv, H.; Fu, Y.; Liu, J.; Li, X.; Bai, Y.-J. Li-ion storage performance of MnO nanoparticles coated with nitrogen-doped carbon derived from different carbon sources. Electrochim. Acta 2014, 146, 249-256. [CrossRef]

37. Kumar, N.A.; Baek, J.-B. Electrochemical supercapacitors from conducting polyaniline-graphene platforms. Chem. Commun. 2014, 50, 6298-6308. [CrossRef]

38. Thapaliya, B.P.; Do-Thanh, C.L.; Jafta, C.J.; Tao, R.; Lyu, H.; Borisevich, A.Y.; Yang, S.Z.; Sun, X.G.; Dai, S. Simultaneously Boosting the Ionic Conductivity and Mechanical Strength of Polymer Gel Electrolyte Membranes by Confining Ionic Liquids into Hollow Silica Nanocavities. Batter. Supercaps 2019. [CrossRef]

39. Qiu, S.; Lu, G.; Liu, J.; Lyu, H.; Hu, C.; Li, B.; Yan, X.; Guo, J.; Guo, Z. Enhanced electrochemical performances of MoO 2 nanoparticles composited with carbon nanotubes for lithium-ion battery anodes. RSC Adv. 2015, 5, 87286-87294. [CrossRef]

40. Lyu, H.; Li, P.; Liu, J.; Mahurin, S.; Chen, J.; Hensley, D.K.; Veith, G.M.; Guo, Z.; Dai, S.; Sun, X.G. Aromatic Polyimide/Graphene Composite Organic Cathodes for Fast and Sustainable Lithium-Ion Batteries. ChemSusChem 2018, 11, 763-772. [CrossRef]

41. Wang, L.; Lu, X.; Lei, S.; Song, Y. Graphene-based polyaniline nanocomposites: Preparation, properties and applications. J. Mater. Chem. A 2014, 2, 4491-4509. [CrossRef]

42. Tong, Y.; Lyu, H.; Xu, Y.; Thapaliya, B.P.; Li, P.; Sun, X.-G.; Dai, S. All-solid-state interpenetrating network polymer electrolytes for long cycle life of lithium metal batteries. J. Mater. Chem. A 2018, 6, 14847-14855. [CrossRef] 
43. Thapaliya, B.P.; Jafta, C.J.; Lyu, H.; Xia, J.; Meyer, H.M., III; Paranthaman, M.P.; Sun, X.G.; Bridges, C.A.; Dai, S. Fluorination of MXene by Elemental $F_{2}$ as Electrode Material for Lithium-Ion Batteries. ChemSusChem 2019, 12, 1316-1324. [CrossRef] [PubMed]

44. Pruneanu, S.; Veress, E.; Marian, I.; Oniciu, L. Characterization of polyaniline by cyclic voltammetry and UV-Vis absorption spectroscopy. J. Mater. Sci. 1999, 34, 2733-2739. [CrossRef]

45. Zhang, J.; Tu, J.P.; Zhang, D.; Qiao, Y.Q.; Xia, X.H.; Wang, X.L.; Gu, C.D. Multicolor electrochromic polyaniline- $\mathrm{WO}_{3}$ hybrid thin films: One-pot molecular assembling synthesis. J. Mater. Chem. 2011, 21, 17316-17324. [CrossRef]

46. Huang, W.S.; MacDiarmid, A.G. Optical properties of polyaniline. Polymer 1993, 34, 1833-1845. [CrossRef]

(C) 2019 by the author. Licensee MDPI, Basel, Switzerland. This article is an open access article distributed under the terms and conditions of the Creative Commons Attribution (CC BY) license (http://creativecommons.org/licenses/by/4.0/). 